
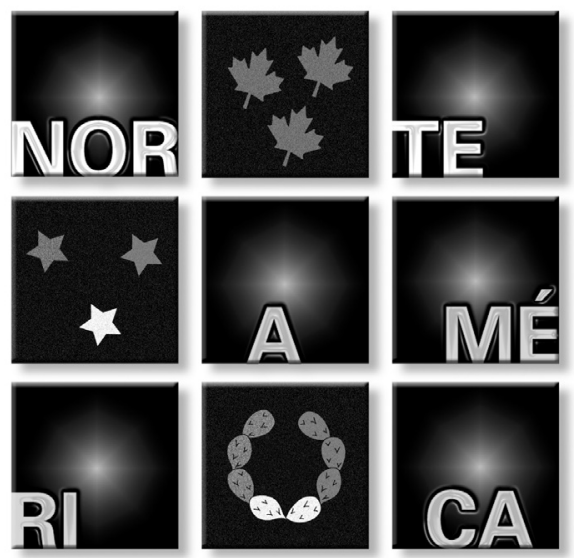

\title{
REFLEXIONES / REFLECTIONS
}

Nota cRítica / Critical Note

Trump y sus dos años de deshonestidad polémica: enfermedades preexistentes en las elecciones intermedias de 2018

David Mena Alemán 



\section{Trump y sus dos años de deshonestidad polémica: enfermedades preexistentes en las elecciones intermedias de 2018 Trump and His Two Years of Polemical Dishonesty, Preexisting Conditions in the 2018 Midterm Elections}

David Mena Alemán*

\section{INTRODUCCIÓN: UN LIDERAZGO SISTEMÁTICO-DISRUPTIVO}

En los mítines de la campaña electoral de Donald Trump, sus seguidores no discuten ninguna de sus afirmaciones, suscriben todo lo que Trump imputa a los demócratas: estos últimos pagan a los centroamericanos para que se sumen a la caravana, no quieren apoyar una nueva legislación para los dreamers ni negociar una nueva para el control de la migración. Todas las imputaciones son seguidas por coreos de asombro e indignación por parte de los seguidores, acción que refrenda la pertinencia de los ataques del presidente estadunidense. Al mostrar su apoyo entusiasta en los mítines de sus campañas, sus seguidores atraen a otros ciudadanos a unirse al movimiento, quienes lo apoyan a cambio de ningún bien material. Son seguidores fervientes. Lo único que obtienen, desde luego, son gratificaciones simbólicas: se saben parte de una población blanca que tiene prioridad en el orden social, y coquetean peligrosamente con la idea de su predominancia esperando la subordinación de otras razas.

La fantasía de superioridad racial no toma en cuenta condiciones socioeconómicas, y éstas no condicionan la pertenencia al grupo racial, todos constituyen una gran familia blanca. Puede más el pudor racial que la situación socioeconómica. La inclusión social económica es menos importante que la racial, Trump promete esta inclusión a todos los seguidores, es la mayor de las gratificaciones. Otra gratificación de la que son partícipes son los insultos que Trump profiere contra ciudadanos de otras razas, por ejemplo, los jugadores afroamericanos de la NFL que se arrodillan cuando se toca el himno nacional, o los "bad hombres"

\footnotetext{
*Instituto Tecnológico Autónomo de México (ITAM), <david.mena@itam.mx>.
} 
La base electoral de un político es lo que condiciona su conducta o actuación, pero es Trump quien condiciona tanto a sus seguidores como al sistema político en su conjunto. mexicanos y musulmanes, que son una amenaza a la seguridad. $Y$ no es que se gane el voto de sus seguidores, sino que los encanta con sus rituales y exabruptos. Los seguidores no son electores normales que reclaman sus derechos y piden cuentas a sus gobernantes, son admiradores incondicionales, una base electoral resilente como la vieja guardia de Napoleón.

Trump puede lograr conquistas electorales con estos admiradores, contrario a lo que otros políticos no podrían con ciudadanos ordinarios. Son un ejército electoral que recurre a formas no convencionales de participación política, guiados por el menos convencional de los líderes políticos. Esto implica ventajas estratégicas que los demócratas no pueden contener, entre otras razones, porque la base electoral de un político es lo que condiciona su conducta o actuación, pero, en el caso de Trump, es él quien condiciona tanto a sus seguidores como al sistema político en su conjunto. Enuncio a continuación las formas como condiciona a sus contrincantes:

Todo lo que imputa a los demócratas en los medios cuenta, nada se desperdicia en virtud de ser absolutamente falso, todo lo que dice Trump cae en tierra fértil. A ninguno de sus seguidores le perturba o apena la falta de pruebas o evidencia.

Cualquier exceso en el que Trump pudiera incurrir, como ejercer presión sobre el gobierno de otro país para que su hija obtenga patentes; desviar recursos de su fundación filantrópica para cubrir gastos de campaña; que salgan a la luz pública sus abusos sexuales e infidelidades; negarse a pagar servicios prestados por terceros, ninguna de esas acciones constituye una iniquidad o injusticia para los seguidores.

Trump puede admirar y desear aliarse con líderes de países no democráticos que tienen capacidad nuclear y menospreciar a los aliados tradicionales de Estados Unidos, y esto no afecta en ningún sentido la lealtad de los ciudadanos seguidores. Aunque se difunda que Putin o Kim Jong Un eliminan sin escrúpulo a sus enemigos políticos, esto podría incluso parecer a los seguidores una conducta aceptable e incluso admirable. Como Trump dice que Putin o Kim Jong Un son admirables, ¡sus seguidores también!

Trump puede contar con un apoyo casi incuestionable de parte de los evangélicos siempre y cuando él mantenga incólume su apoyo a la declaración de inconstitucionalidad del caso Roe vs. Wade. La reciente integración a la Suprema Corte de Brett Kavanaugh sella para siempre la lealtad de los evangélicos a Trump. Dicha inclusión implica la muerte de Roe vs. 
Wade en un futuro muy cercano. Y no es problemático para los seguidores que las mujeres no ejerzan su derecho al control sobre su propio cuerpo.

Trump moviliza a sus bases con declaraciones completamente falsas tanto en sus make America great again como en sus entrevistas con los medios. Advierte, sin escrúpulo alguno, que personas de Medio Oriente se ocultan en el contingente de la caravana proveniente de Centroamérica, que los demócratas organizaron dicha caravana, que Obama fue el fundador del Islamic State of Iraq and al-Sham, que los californianos están tan inconformes con la política de las ciudades santuario que se han amotinado para abolirlas, entre otras declaraciones.

Como ha sido patente en los últimos dos años, ha convertido sus declaraciones (altamente imprecisas o abiertamente falsas) en armas poderosas para derrotar a sus opositores; en su inmensa osadía, ha logrado que se crea cualquier interpretación que haga de la realidad. En general, puede recurrir a sus mentiras porque es imposible desmentirlas, por ejemplo, a lo que nos referíamos respecto a la caravana centroamericana. En ambos casos, no asume la carga de la prueba, que sería lo lógico para dar sustento a su presunción. De todos modos, puede declarar que el FBI es una desgracia, así como también las fake news, porque ni el FBI ni los medios han mandado gente a sumarse a la caravana para verificar si están o no las personas de Medio Oriente. Parece que Trump asume que goza de la prerrogativa de presumir lo que quiera y que a los demás les corresponde verificar lo que presume.

No obstante, en el actual proceso electoral intermedio, Trump ha tenido dificultad para contrarrestar un tema crítico: el de las condiciones de enfermedades preexistentes. Este tema no se presta a los usos que suele dar a la mayoría de los temas electorales. Por un lado, lo que presumen los demócratas sobre el tema es suficientemente verificable como para desmentir cualquier presunción del presidente. Por otro lado, la verificabilidad hace que se revalore una política pública de la era de Obama, que sirva como estándar para comparar las propuestas republicanas respecto a los seguros médicos. La discusión del tema sobre condiciones preexistentes de enfermedad a lo largo del periodo electoral intermedio tuvo efectos devastadores para algunos candidatos, efectos que Trump no pudo manipular a su favor.

Lo que molesta tanto a los medios como a los demócratas es que las bases populares y los grupos de interés económico que apoyan al presidente no lo frenan; entonces, nada detiene su producción de ficciones. Cuando
Donald Trump ha convertido sus declaraciones (altamente imprecisas o abiertamente falsas) en armas poderosas para derrotar a sus opositores; en su inmensa osadía, ha logrado que se crea cualquier interpretación que haga de la realidad. 
Trump abrió fuego contra los demócratas en la campaña aventurando la más osada de sus mentiras, a saber, que "los demócratas jamás... [garantizarán] que se obligue a las aseguradoras a dar cobertura a individuos con condiciones preexistentes de enfermedad" durante el tiempo de Obama, los autores de las protecciones contra tales condiciones, las mentiras de Trump perdieron su efecto y algunos de sus candidatos, además de hacer el ridículo, perdieron las elecciones.

\section{La batalla ElEctoral POR SALVAR Obamacare}

Con la victoria del

Partido Republicano en 2016, se buscó implementar la política más importante del gobierno de Trump, la Ley de Reducción de Impuestos que tangencialmente tuvo una repercusión fatal sobre la legislación en salud que había creado Obama.
Para entender la relevancia del tema sobre condiciones preexistentes de enfermedad, debe saberse que se trata de un requisito de la Ley de Salud (Health Care Law), denominada Ley de Salud Asequible (Affordable Care Act [ACA] u Obamacare), aprobada en marzo de 2010. El requisito más relevante establece que las aseguradoras "no han de imponer ninguna exclusión de condición preexistente" (Greenberg, 2018). Este requisito supone un principio de justicia social de cara al cual, de acuerdo con Rodney Whitlock, experto en política de salud, "gente que no sufre condiciones preexistentes paga más [por su seguro] para proteger a la gente que sí padece tales condiciones" (Greenberg, 2018).

Con la victoria del Partido Republicano en 2016, se buscó implementar la política más importante del gobierno de Trump, la Ley de Reducción de Impuestos (fundamentada en el Act to Provide for Reconciliation Pursuant to Titles II and V of the Concurrent Resolution on the Budget for Fiscal Year 2018 o Tax Cuts and Jobs Act, aprobada el 2 de noviembre de 2017), que tangencialmente tuvo una repercusión fatal sobre la ACA. La Ley de Reducción de Impuestos de 2017 contenía, a su vez, el requisito de reducir a cero las multas aplicables a los ciudadanos que no tuvieran cobertura. En otros términos, la Ley de Reducción de Impuestos de 2017 suprimió la provisión de mandato individual, con base en que "las compañías [aseguradoras] estaban forzadas a dar cobertura a todos [los ciudadanos]. Así, el gobierno entonces forzaría a todos [con algunas excepciones] a tener un seguro" (Greenberg, 2018), con el fin de que los sanos cubrieran los costos adicionales en los que incurrieran los que presentan condiciones de enfermedad preexistentes. En otras palabras, una ley sobre impuestos dejará sin efecto un programa de seguridad social al hacer voluntaria (en lugar de obligatoria) la adquisición individual de cobertura. No obstante, 
como la ley 2017 de reducción de impuestos no era retroactiva, continúa siendo vigente la ACA sobre sus asegurados de 2010 a 2018, a pesar de varios intentos republicanos por abolirla. Como esta situación no fue suficientemente satisfactoria para los republicanos representantes de dueños de aseguradoras, pocos meses después de haberse aprobado la ley sobre impuestos de 2017 "fue presentada una demanda (Texas vs. Estados Unidos; Caso 4:18-cv-00167-O, Documento 91, demanda 06/07/2018) por dieciocho abogados generales estatales y dos gobernadores" para suprimir las protecciones de la ACA sobre aquellos que padecen condiciones preexistentes (Bradner, Krieg et al., 2018). De acuerdo con Jacob Pramuk, tales abogados y gobernadores argumentaron que la Ley Completa de Salud Asequible dejó de tener sustento a partir del momento en que los republicanos se deshicieron de la provisión de mandato individual de la ley sobre impuestos que antecedió a la de 2017 (Pramuk, 2018). Todo esto tuvo lugar antes de que iniciara el proceso electoral intermedio. En todo caso, queda claro que los republicanos dejaron la ACA sin capacidad para integrar a nuevos solicitantes después de 2019, como lo venía haciendo desde marzo de 2010. También está claro que han iniciado un juicio para que la ACA se extinga y sea sustituida con un esquema de seguro médico diseñado por los republicanos de acuerdo a los intereses de las aseguradoras.

Para terminar con el esquema de aseguramiento obligatorio de la ACA y previendo que éste sería un asunto relevante de la campaña electoral, diez senadores republicanos -Dean Heller (Nevada), Thom Tillis (Carolina del Norte), Lamar Alexander (Tennessee), Chuck Grassley (Iowa), Bill Cassidy (Louisiana), Joni Ernst (Iowa), Lindsey Graham (Carolina del Sur), John Barrasso (Wyoming), Lisa Murkowski (Alaska) y Roger Wicker (Mississippi)- enviaron al Senado, en agosto de 2018, la Iniciativa S.3388 Ley para Asegurar la Cobertura de Pacientes con Condiciones Preexistentes (Ensuring Coverage for Patients with Pre-Existing Conditions Act). Ésta no puede entrar en vigor hasta que el juez del Distrito Norte de Texas, Reed O'Connor, decida si se terminan las protecciones de condiciones preexistentes de la ACA (Keith, 2018), que es una ley vigente, en virtud de que el mandato individual vinculado a dichas protecciones dejó de ser obligatorio para todo ciudadano por efecto de la ley impositiva de 2017. Es por demás extraño que las protecciones mencionadas sean abolidas para después volver a ser vigentes en el marco de la Ley para Asegurar la Cobertura de Pacientes con Condiciones Preexistentes (en adelante, Ley para Asegurar...). Sólo podría haber una garantía en el hecho de permitir
Una ley sobre impuestos dejará sin efecto un programa de seguridad social al hacer voluntaria (en lugar de obligatoria) la adquisición individual de cobertura; será sustituido por un esquema de seguro médico diseñado por los republicanos de acuerdo a los intereses de las aseguradoras. 
La nueva legislación republicana tiene una concepción de condiciones preexistentes de enfermedad mucho más débil que la prevista por la administración de Obama. a las aseguradoras sacudirse y deshacerse de ciertas obligaciones que imponía la ACA. En este respecto, Alisson Hoffman aclara, citando la Ley para Asegurar... (sección 196, e, 1-B), “que las aseguradoras pueden [...] negar cobertura a [empleadores e] individuos [...] si demuestran que no tendrán la capacidad de prestarles servicios adecuadamente" (Greenberg, 2018; Congress, 2018). Es previsible que las aseguradoras alegarán carecer de capacidad para prestar sus servicios a personas con condiciones preexistentes si el tratamiento de tales condiciones llegara a ser financieramente desquiciante. Esto era precisamente lo que la ACA garantizaba en su esquema colectivo de transferencias de recursos de sanos a enfermos crónicos. También, Greenberg señala que, aunque la Ley para Asegurar... "no establece reglas de elegibilidad, basadas en condiciones actuales de salud, condición médica, promedio de reembolsos de gastos médicos e historial médico", sí permite a las aseguradoras establecer tarifas con base en factores diferentes a los mencionados (Greenberg, 2018). Por lo demás, advierte Hoffman, las aseguradoras "también pueden cobrar más caro el servicio que prestan de acuerdo a las condiciones de sanidad del área de residencia y de la ocupación laboral"; asimismo, introducirían más escalas de tarifas por diferencias de edad (Greenberg, 2018). Mientras que la ACA establecía que la tarifa máxima no podía ser mayor a tres veces la tarifa aplicada al asegurado más joven, la Ley para Asegurar... puede cobrar la tarifa al asegurado más joven tantas veces como la aseguradora considere necesario. Y, en general, como menciona Whitlock, "las aseguradoras usarán las reglas existentes para que la cuantía de los premios siempre supere la suma de los pagos de reembolso" (Greenberg, 2018).

Las diferencias entre la ACA y la Ley para Asegurar... ponen de manifiesto que la segunda tiene una concepción de condiciones preexistentes mucho más débil que la ACA. En general, la segunda tiene como prioridad generar un sector de seguros médicos financieramente saludable a costa de excluir un número mucho mayor de personas afectadas por condiciones preexistentes de las que la ACA habría permitido. Las modalidades de exclusión de los afectados por condiciones preexistentes en la Ley para Asegurar... pueden darse, ya sea por la incapacidad de pago del asegurado o por el rechazo de la aseguradora en previsión de que sería incapaz de prestar adecuadamente sus servicios.

En vista de la secuencia de eventos, partiendo del hecho de que los senadores republicanos intentaron, pero no pudieron, abolir la ACA en dos ocasiones (gracias al voto en contra emitido por el senador republi- 
cano John McCain); de que lograron indirectamente desarticular la ACA al eliminar la obligación clave de aseguramiento obligatorio implicada en la provisión del mandato individual, con la Ley 2017 de Reducción Impositiva; y de que posteriormente llevaron a juicio la ACA, en el caso Texas vs. Estados Unidos, con el propósito de suprimir las protecciones de condiciones preexistentes de la ACA y de, en última instancia, sustituirlas por la Ley para Asegurar... que, como hemos visto, permitirá a las aseguradoras ignorar solicitudes de aseguramiento provenientes de personas con condiciones preexistentes, o bien les permitirá encarecer las pólizas de seguros para que tales personas desistan, vemos claramente que la disputa entre republicanos y demócratas se reduce a un choque entre los intereses económicos del lobby de las aseguradoras, así como la necesidad concreta de facilitar acceso a servicios médicos, especialmente a los sectores de menor ingreso, y garantizar así algo que se aproxime a una cobertura universal de salud. Veremos en la siguiente sección qué tanto afectó a los republicanos su defensa pública de los intereses del lobby de las aseguradoras durante las elecciones intermedias de 2018, y a qué tretas recurrieron para eludir los costos de su apoyo a dicho lobby.

Un par de meses después de que el juez Reed O'Connor escuchó las posiciones de los involucrados en el caso Texas vs. Estados Unidos, iniciaron las elecciones intermedias de 2018. Recuérdese que esta querella busca que se suprima la protección de condiciones preexistentes, y el hecho de que los republicanos hayan suscrito esta querella los presenta en la justa electoral como enemigos del Obamacare. Eric Bradner y Dan Merica señalan que, en al menos ocho estados donde se disputa la gubernatura, los demócratas presentaron comerciales que identifican a los aspirantes a gobernador, firmantes del juicio federal Texas vs. Estados Unidos como Patrick Morrisey (Virginia del Oeste), Mark DeWine (Ohio), Scott Walker (Wisconsin), Bill Schuete (Michigan) y Josh Hawley (Missouri). Todos destacan por su aversión a la cobertura de condiciones preexistentes (Bradner y Merica, 2018). Al ser identificados como firmantes, DeWine y Morrisey difícilmente podían afirmar que eran defensores de la cobertura de condiciones preexistentes. Por su parte, Walker, que aspira a ser reelecto como gobernador, al reconocer públicamente que suscribió la querella, advirtió que si la Corte se decidiera a favor de los republicanos, "convocaría una sesión especial de la legislatura estatal para aprobar una ley requiriendo cobertura de condiciones preexistentes". Bill Schuete llegó al extremo de invitar a un panel a personas con condiciones preexis-
La disputa entre republicanos y demócratas se reduce a un choque entre los intereses económicos del lobby de las aseguradoras, así como la necesidad concreta de facilitar acceso a servicios médicos, especialmente a los sectores de menor ingreso. 
tentes para presentar sus preocupaciones ante los medios, buscando demostrar su interés en el tema y contrarrestar los cargos que le había hecho su contrincante, la demócrata Gretchen Whitmer, quien advierte en un comercial que Shuete "piensa que se debe permitir que las compañías de seguros nieguen cobertura a personas con condiciones preexistentes" (Frost, 2018). La estrategia de defensa de Josh Hawley, ante los ataques de su contrincante la senadora Claire McCaskill llevó a Hawley a hacer un comercial "en el que dice que él y su esposa descubrieron este año que su hijo mayor tiene una 'enfermedad crónica rara' [...], que es una condición preexistente, y que por eso apoya a que se fuerce a las compañías de seguros a cubrir todas las condiciones preexistentes" (Bradner, Krieg et al., 2018). De manera similar, el senador republicano Dean Heller responde a un cuestionamiento de la congresista demócrata Jacky Rosen, alegando que "él tiene dos nietos con condiciones preexistentes" (Bradner, Krieg et al., 2018).

En vista de los ejemplos anteriores, lo primero que destaca es que ni por asomo los republicanos asumen que el problema de la propuesta de su seguro de salud es que no tiene por objeto una cobertura universal y,

Ni por asomo los republicanos asumen que el problema de la propuesta de su seguro de salud es que no tiene por objeto una cobertura universal y, por lo tanto, es previsible que abandone a su propia suerte a un sector de la población con condiciones preexistentes. por lo tanto, es previsible que abandone a su propia suerte a un sector de la población con condiciones preexistentes. Esto sugiere que la propuesta republicana de seguro de salud parte de una premisa de autoprovisión del individuo (Simmons, 2001: 36-37). Esta premisa, combinada con la de "separatividad" de las personas, que establece que los individuos no son susceptibles de reclamos de transferencias gratuitas por parte de otros individuos (Kymlicka, 2002: 108, 124), genera un horizonte trágico para los individuos con enfermedades gravosas, pues si ellos no generaron los ingresos suficientes para pagar primas muy elevadas que cubran sus gastos, se asume que es su responsabilidad, y de nadie más, cubrir sus propias necesidades de atención médica. Entonces, el principal problema de los republicanos es que no les gusta decir públicamente que son completamente indiferentes hacia las personas que sufren enfermedades graves y que no pueden autoproveerse de los bienes y servicios médicos que necesitan, pero sí les gusta decir que cada individuo debe valerse por sí mismo. Todo esto complica la discusión de condiciones preexistentes. Además, parte de la discusión se resolvería con la aclaración de que los republicanos prefieren una política de seguros que cubra las condiciones preexistentes de los que las sufren, pero que no obligue a nadie a contribuir a la atención médica de otros que padezcan tales condiciones: 
está bien enfrentar por cuenta propia las condiciones preexistentes de uno, pero no las de otros. Si los republicanos se condujeran de manera honesta, tendrían que aclarar que son defensores de la cobertura de condiciones preexistentes y que están de acuerdo con que las primas de sus seguros varíen tanto como la gravedad de la enfermedad que se les diagnostique; si se altera mucho y el enfermo tiene muchos recursos, podrá cubrir los costos de su tratamiento de acuerdo a los términos de su póliza, pero si el enfermo no tiene muchos recursos y los costos de su tratamiento son superiores a sus ahorros, entonces no podrá aportar los costos de coaseguro y nada se hará para atenderlo. Entonces, cuando el republicano Walker dice que aprobará una ley estatal requiriendo cobertura de condiciones preexistentes, sólo puede asegurar de que se ocupen de tales condiciones de acuerdo a su gravedad y como lo señala la Ley para Asegurar...; es posible que, en el caso de algunos individuos, la aseguradora decline prestarles atención médica por temor de que no tengan la capacidad para prestar de manera adecuada los servicios que requieren los individuos. Ahora bien, si Walker no se refiere a esto, entonces su alternativa sería una ACA u Obamacare estatal, en el que todos los ciudadanos estén asegurados, los que no lo estuvieran pagarían una multa por no asegurarse y los sanos contribuirían con los gastos adicionales de los ciudadanos que sufren condiciones preexistentes, sin importar cuanto varíe la gravedad de tal condición. Pero entonces Walker estaría implementando una política de seguridad social típicamente demócrata.

Es muy posible que a los candidatos republicanos les haya quedado muy claro que no tenían más opción que la de hacer el ridículo, dado que los demócratas no los iban a dejar hablar de ningún otro tema que no fuera "condiciones preexistentes" y de que la propuesta de la Ley para Asegurar... no se prestaba para la discusión pública en la campaña, pues implicaba muy malas noticias para los pobres e incluso para los ricos muy enfermos. En tales circunstancias, no es raro que Shuete en su conferencia de prensa de personas con condiciones preexistentes, Hawley con su empeño por generar empatía pública hacia la "enfermedad crónica rara" de su hijo y "los dos nietos (de Heller) con condiciones preexistentes", sugieren que ni siquiera los republicanos pudieron justificar la Ley para Asegurar... Uno no puede más que concluir que será una decisión fatal suprimir la ACA, pues, a cambio de tolerar un esquema de cooperación forzada, prometía no abandonar a ningún ciudadano a su propia suerte, fuera cual fuere su situación económica. Por lo demás, cuando Trump se
Parte de la discusión se resolvería con la aclaración de que los republicanos prefieren una política de seguros que cubra las condiciones preexistentes de los que las sufren, pero que no obligue a nadie a contribuir a la atención médica de otros que padezcan tales condiciones. 
Trump introdujo la mentira sistemática a la política estadunidense, lo que no habla tan mal de él como de sus seguidores, que tienen un bajísimo nivel educativo y que su poca educación los convirtió en presas de manipuladores. anima a advertir que "los demócratas jamás van a garantizar que se obligue a las aseguradoras a dar cobertura a individuos con condiciones preexistentes de enfermedad", puede decirse que los demócratas se aseguraron de que se diera cobertura a individuos con tales condiciones, sin distinción del nivel de gravedad, que el juez Reed O'Connor hará saber si suprimen o no las protecciones de esas condiciones. Esto prueba contundentemente que los demócratas sí garantizaron dicha obligación; de otro modo, el juez Reed O'Connor no tendría nada que suprimir.

\section{Conclusiones}

Trump introdujo la mentira sistemática a la política estadunidense, lo que no habla tan mal de él como de sus seguidores. Sus amigos millonarios fingen, pero sus seguidores realmente creen que Trump dice la verdad y eso es patético, pues no puede más que sugerir que tienen un bajísimo nivel educativo y que su poca educación los convirtió en presas de manipuladores. Por lo demás, la fantasía racial hace a los seguidores de Trump perder de vista su propio bien, pues la ACA ofrece la garantía de que aún las peores condiciones son objeto de atención con base en el principio de que los sanos asegurados deben contribuir colectivamente a los costos adicionales en que incurren los más afectados por condiciones preexistentes. Como la afiliación es obligatoria hasta finales de diciembre de 2019, seguro cuentan a la fecha con Obamacare. No obstante, no debe descartarse la posibilidad de que la autoalienación de los seguidores de Trump llegue al extremo de que éstos celebren su propia ruina, buscando desafiliarse de la ACA si el juez Reed O'Connor decide extinguirlo. Pero al menos la discusión pública sobre este tema, por tener referentes claros, caló hondo y abrió un frente de batalla productivo que comenzó a favorecer a los demócratas, aunque hay que reconocer que el tema de cobertura de condiciones preexistentes es muy complejo y que gente con poca educación podría no ver diferencias significativas entre un seguro basado en solidaridad colectiva como la ACA y uno en descuentos para los sanos y primas para los más enfermos como el tipo de seguros que ofrece la Ley para Asegurar... Ahora que los demócratas tienen la mayoría en la Cámara de Representantes, podrían montar una defensa más efectiva de las protecciones a las condiciones preexistentes. 


\section{FUENTES}

\section{BRADNER, ERIC y DAN MERICA}

2018 "Health Care Takes Center Stage in Midterms Fight and Republicans Are on the Defensive", CNN, 26 de septiembre, en <https: / / edition.cnn.com/2018/09/26/ politics / republicans-health-caredefensive/index.html>, consultada el 15 de octubre de 2018.

\section{Bradner, ERIC, GRegory KRIEG y TAMI LuHby}

2018 "Republicans' Health Care Strategy for the Midterms: Fear and Misdirection", CNN, 26 de octubre, en <https: / / edition.cnn.com/ 2018/10/25/ politics / republicans-health-care-midterms-false hoods / index.html>, consultada el 27 de octubre de 2018.

\section{CONGRESS}

2018 "Ensuring Coverage for Patients with Pre-Existing Conditions Act", Congress, 23 de agosto, en <https://www.congress.gov/ 115/ bills / s3388/BILLS-115s3388is.pdf>, consultada el 9 de noviembre de 2018 .

\section{Frost, MikenZIE}

2018 “Schuete 'Sets Record Straight' about Pre-Existing Conditions; Whitmer Says “Baloney'”, West Michigan, 8 de octubre, en <https: / / wwmt.com/news/state/ schuette-sets-record-straight-about-preexisting-conditions-whitmer-says-baloney $>$, consultada el 28 de octubre de 2018.

GreEnBerG, Jon

2018 "Pre-existing Conditions: Does any GOP Proposal Match the ACA?", Politifact, 17 de octubre, en <https:/ / www.politifact.com/trutho-meter / article / 2018 / oct / 17 / pre-existing-conditions-does-anygop-proposal-matc/>, consultada el 22 de octubre de 2018.

\section{Keith, Katie}

2018 "Judge Hears Oral Arguments In Texas vs. United States", Health Affairs, 10 de septiembre, en <https:/ / www.healthaffairs.org/ do/10.1377/hblog20180910.861789/full/>, consultada el 9 de noviembre de 2018 . 
KYMLICKA,WILL

2002 Contemporary Political Philosophy: An Introduction, Nueva York, Oxford University Press.

PRAMUK, JACOB

2018 "Trump Keeps Promising to Protect Pre-existing Condition Coverage but His Policies Say Otherwise", CNBC, 24 de octubre, en $<$ https: / / www.cnbc.com/2018/10/24/ trump-pledges-to-protectobamacare-pre-existing-conditions-as-midterms-loom.html>, consultada el 25 de octubre de 2018.

Simmons, A. JoHN

2001 Justification and Legitimacy: Essays on Rights and Obligations, Nueva York, Cambridge University Press. 